\title{
DEFINIÇÃO DE CRITÉRIOS PARA DELIMITAÇÃO DE MORROS CATEGORIZADOS COMO SÍTIOS DE RELEVANTE INTERESSE PAISAGÍSTICO E AMBIENTAL NO MUNICÍPIO DO RIO DE JANEIRO
}

\author{
Edinaly dos Santos Freire ${ }^{\text {(a) }}$ \\ (a) DGF/IGEOG, Universidade do Estado do Rio de Janeiro, edinalyfreire@ yahoo.com.br
}

Eixo: 12. Uso e Ocupação das Terras e Legislação Ambiental

\begin{abstract}
Resumo
O Plano Diretor da cidade do Rio de Janeiro (LEI COMPLEMENTAR n ${ }^{\circ}$ 111/2011) instituiu os Sítios de Relevante Interesse Paisagístico e Ambiental. Estes, que são listados no referido documento, apresentam entre as formações a serem protegidas alguns morros. Baseando-se na Resolução CONAMA 303, desse modo, busca-se definir os critérios mais adequados para delimitação das bases de cada uma dessas formações e sugerir o procedimento prático a ser executado. Para tal, foi realizada uma interpretação de atos legais, levantamento bibliográfico e, análise espacial de Ortofotos Digitais e curvas de nível. Gerou-se como produto, portanto, duas tabelas: uma contendo os critérios e procedimentos a serem adotados para delimitação das bases e outra discriminando os morros e os respectivos critérios definidos; e, um conjunto de mapas com a espacialização dos dados da segunda tabela.
\end{abstract}

Palavras chave: Plano Diretor; Sítios de Relevante Interesse Paisagístico e Ambiental; Morros; Delimitação; Resolução CONAMA 303

\section{Introdução}

O Plano Diretor Decenal da Cidade do Rio de Janeiro (LEI COMPLEMENTAR n 16/1992) previa em seu capítulo V, "das diretrizes de uso e ocupação por áreas de planejamento", que alguns elementos da paisagem do município seriam considerados Patrimônio Paisagístico, estando assim sujeitos a algum tipo proteção ambiental. Entretanto, esse mesmo documento não estabelecia parâmetros restritivos para tal definição, nem tampouco apresentou outro ato legal subsequente que o fizesse.

Em 2011 foi realizada uma atualização do documento citado, dando origem ao Plano Diretor de Desenvolvimento Urbano Sustentável (PDDUS) do município do Rio de Janeiro (LEI COMPLEMENTAR n¹11/2011), que revoga a lei anterior (LEI COMPLEMENTAR n¹6/1992), trazendo consideráveis modificações. No capítulo IV, "dos instrumentos de gestão ambiental e cultural”, subseção IV, é instituída uma nova categoria de Áreas Protegidas denominada Sítios de Relevante Interesse Paisagístico e Ambiental (SRIPA), que são: 
XVII Simpósio Brasileiro de Geografia Fisica Aplicada

I Congresso Nacional de Geografia Física
OS DESAFIOS DA GEOGRAFIA FÍSICA NA FRONTEIRA DO CONHECIMENTO

Instituto de Geociências - Unicamp

Campinas - SP

28 de Junho à 02 de Julho de 2017

[...] áreas, de domínio público ou privado que, por seus atributos naturais, paisagísticos, históricos e culturais, constituam-se em referência para a paisagem da Cidade do Rio de Janeiro, sujeitas a regime de proteção específico e a intervenções de recuperação ambiental, para efeitos de proteção e manutenção de suas características. (LEI COMPLEMENTAR n ${ }^{\circ} 111 / 2011$ )

Os SRIPA agrupam em incisos algumas das áreas antes entendidas legalmente como Patrimônio Paisagístico, porém, trazendo nessa atual versão do Plano Diretor parâmetros que determinam limitações específicas para essas áreas. A possível exigência de um "Estudo de Impacto Ambiental ou de Vizinhança e respectivos relatórios" (LEI COMPLEMENTAR n 111/2011), no caso de intervenções nessas áreas, é um exemplo dessas restrições.

Consequentemente a isso, o conhecimento dos limites para um manejo e controle adequado desses ambientes torna-se essencial, fazendo com que os Sítios de Relevante Interesse Paisagístico e Ambiental, assim como as demais categorias de proteção, precisem ser delimitados espacialmente. Tanto o Planejamento Ambiental e Gestão do Território quanto o Licenciamento Urbano e Ambiental são áreas que demandam esse tipo de dado.

Partindo dessa premissa, a Secretaria Municipal de Conservação e Meio Ambiente (SECONSERMA) do Rio de Janeiro, desde novembro de 2016, está atualizando um arquivo de dados espaciais no formato shapefile contendo as Áreas Protegidas da cidade do Rio de Janeiro. Este, incluirá outras categorias citadas no Plano Diretor como objeto de proteção ambiental, mas, a princípio, os esforços estão direcionados para o mapeamento das feições definidas como Sítios.

Na categoria dos SRIPA, como o próprio nome sugere, estão compreendidas áreas tanto de interesse paisagístico quanto ambiental. Aqui, todavia, destaca-se a segunda, uma vez que esta apresenta entre os sítios um tipo de formação geomorfológica conceitualmente emblemática: o morro. Esta feição, devido à diversidade existente nas formas do relevo, que se acentua quando observado em uma escala local, é de difícil definição, principalmente no que concerne ao limite de sua base.

Em função disso, para a delimitação dos morros, foram encontradas limitações conceituais no documento onde estes aparecem - PDDUS -, dificultando assim, a continuidade na atividade em curso. Tendo em vista tal prerrogativa, torna-se relevante, senão essencial, a realização de uma investigação dos documentos legais existentes e metodologias propostas, buscando assim oferecer embasamento conceitual para a delimitação de bases de morros e, que satisfatoriamente atenda as especificidades geomorfológicas da área a ser trabalhada.

Este trabalho, nesse sentido, busca estabelecer critérios, com base em documentos legais, para a delimitação dos morros listados no Plano Diretor da cidade do Rio de Janeiro (LEI COMPLEMENTAR 
$\mathrm{n}^{\circ}$ 111/2011) como Sítios de Relevante Interesse Paisagístico e Ambiental; assim como, propor um procedimento prático para a identificação dessas bases de morro, em função das especificidades do caso e dados disponíveis para utilização.

\section{Metodologia}

O procedimento aplicado para definição dos critérios a serem utilizados para posterior delimitação das bases de morro consistiu, em um primeiro momento, na busca e interpretação de documentos legais. Nessa etapa, foi selecionada a Resolução CONAMA n $303^{1}$ como norteadora do processo a ser executado. Posteriormente, foi realizada uma busca visando encontrar artigos publicados que abordassem a temática aqui proposta e identificar em quais contextos os critérios apontados nesta Resolução foram aplicados. Nessa investigação sobre as pesquisas já realizadas encontrou-se como referência os autores Oliveira e Filho (2013), Victoria et al. (2008), Cortizo (2007) e Costa et al. (1996).

Em seguida, localizou-se os morros considerados SRIPA e fez-se uma análise espacial, com o auxílio de Ortofotos digitais de 2013 (DATUM: SAD 1969) e curvas de nível com intervalo de 5m (Projeção UTM/ DATUM: SAD 1969) - como existe um Modelo Digital de Elevação da cidade, com um intervalo de curva de nível menor, estas serão utilizadas para delimitação da base. Foi então definido para cada ocorrência um dos três critérios possíveis para identificação das bases dos morros, de acordo com a Resolução, os quais foram também interpretados, resultando em sugestões de procedimentos práticos para a delimitação de acordo com o caso em estudo. E, finalmente, foi gerada uma tabela e um conjunto de mapas com os morros e seus respectivos critérios para delimitação da base.

\subsection{Os "morros" no Plano Diretor}

No texto da Lei Complementar 111/2011 são citados os seguintes morros como alvos de proteção ambiental: "da Babilônia, da Catacumba, da Saudade, da Urca, da Viúva, de São João, do Cantagalo (AP2), do Leme, do Pão de Açúcar, do Pasmado, do Urubu (AP-2), dos Cabritos, da Estação, do Retiro, do Taquaral, dos Coqueiros, da Posse, das Paineiras, do Santíssimo, do Luis Bom, do Mirante e do Silvério do Amorim, Panela, do Bruno, do Camorim, do Cantagalo (AP-4), do Outeiro, do Portela, do Rangel e do Urubu (AP-4)" (inciso VIII, artigo 117). Estes morros estão distribuídos nos bairros de Flamengo, Botafogo, Urca, Leme, Copacabana, Humaitá, Lagoa, Ipanema, Barra da Tijuca, Anil, Recreio dos Bandeirantes, Vargem Pequena, Vargem Grande, Camorim, Jacarepaguá, Deodoro, Bangu, Santíssimo, Senador Camará, Senador Vasconcelos, Campo Grande, Santa Cruz e Pedra de Guaratiba, na cidade do Rio de Janeiro (Figura 1).

\footnotetext{
1 A Resolução CONAMA n 303 "Dispõe sobre parâmetros, definições e limites de Áreas de Preservação
} Permanente". 

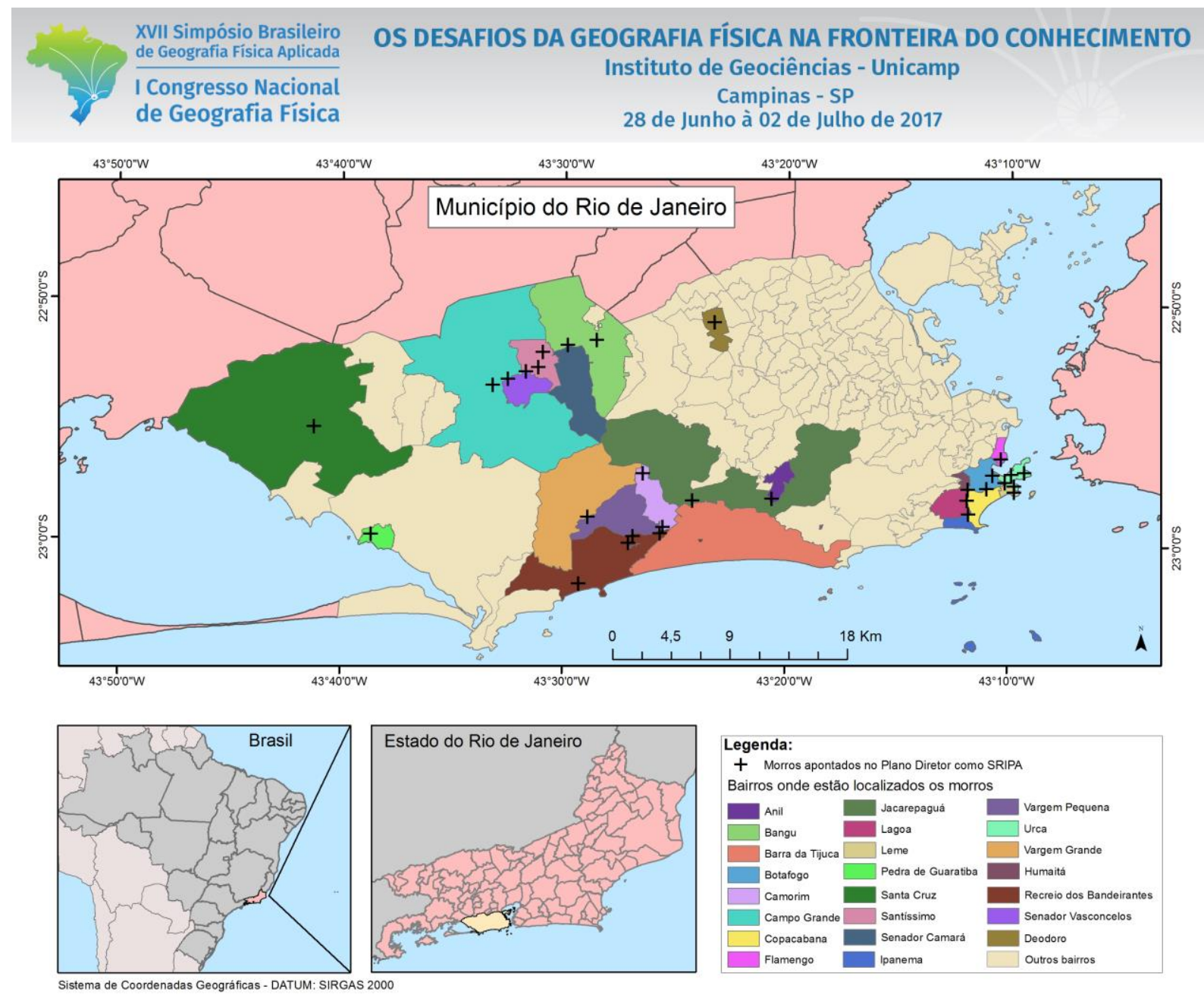

Figura 1 - Localização dos morros em estudo. (Fonte: elaborado pela autora. Base cartográfica de 2010 do IBGE)

Tais formações denominadas SRIPA no Plano Diretor, em alguns casos devido à fragilidade ambiental apresentada, encontram-se também sob proteção de outros instrumentos, reforçando a relevância da preservação das áreas. Quanto às medidas restritivas dispostas no PDDUS, são elas:

$\S 1^{\circ}$ Os sítios acima descritos estão sujeitos, no caso de projetos públicos ou privados, à análise ou avaliação ambiental estratégica pelo órgão central de planejamento e gestão ambiental, podendo ser exigido Estudo de Impacto Ambiental ou de Vizinhança e respectivos relatórios.

$\S 2^{\circ}$ Quaisquer alterações de parâmetros urbanísticos nos sítios acima citados deverão ser objeto de análise e deliberação conjunta entre os órgãos centrais de urbanismo, meio ambiente e patrimônio cultural.

$\S 3^{\circ} \mathrm{Na}$ hipótese de demolição de edificação situada no entorno do Morro da Viúva, o Poder Público instituirá servidão de passagem para assegurar o acesso a esse bem natural e a sua contemplação. (LEI COMPLEMENTAR 111/2011)

Todavia, essas exigências somente são válidas a partir da data de publicação do documento - 2011 - , não apresentando nenhuma medida a ser tomada em caso de usos impactantes pré-existentes à Lei. Como a cidade do Rio de Janeiro constitui uma metrópole nacional, característica principalmente pelo alto grau de urbanização, pressupõe-se que existam casos que firam estas determinações legais. 
XVII Simpósio Brasileiro de Geografia Física Aplicada

I Congresso Nacional

de Geografia Física
OS DESAFIOS DA GEOGRAFIA FÍSICA NA FRONTEIRA DO CONHECIMENTO

Instituto de Geociências - Unicamp

Campinas - SP

28 de Junho à 02 de Julho de 2017

\subsection{Definição de Base de Morro e a Resolução CONAMA n ${ }^{\circ}$ 303/ 2002}

A Resolução CONAMA N³03 (2002), mesmo tendo sido desfuncionalizada com a instituição do Novo Código Florestal (CF) em 2012, é aqui utilizada como referência central por ser um dos poucos documentos oficiais que apresenta as definições de morro e base de morro. A referida atualização do CF é alvo de intensas críticas por parte do meio acadêmico justamente por sua carência de embasamento conceitual e perdas consideráveis quanto à proteção de áreas (VARJABEDIAN\&MECHI).

A Resolução em questão considera:

IV - morro: elevação do terreno com cota do topo em relação a base entre cinqüenta e trezentos metros e encostas com declividade superior a trinta por cento (aproximadamente dezessete graus) na linha de maior declividade;

VI - base de morro ou montanha: plano horizontal definido por planície ou superfície de lençol d’água adjacente ou, nos relevos ondulados, pela cota da depressão mais baixa ao seu redor; (CONAMA 303/2002)

Primeiramente, como sugere Cortizo (2007), é essencial que se faça uma interpretação adequada do texto desta Resolução. Desse modo, entende-se que, para caracterizar uma formação geomorfológica como um morro, é preciso delimitar primeiramente sua base (este artigo limita-se a essa etapa). Para isto, é necessário analisar o entorno da elevação, observando se o morro está próximo a uma planície - a base corresponderá à cota desta -, um espelho d'água - a base será a cota deste - ou em meio a um relevo ondulado - neste caso, a cota altimétrica mais baixa ao seu redor corresponderá a base da elevação. De acordo com essa constatação, define-se o critério a ser utilizado para realizar a delimitação (Figura 2).

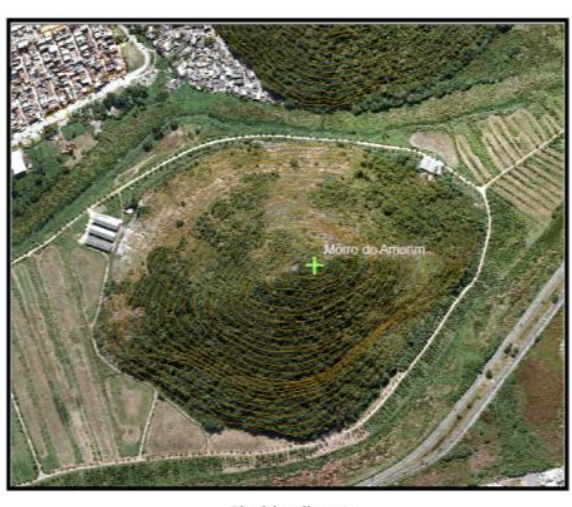

Planície adjacente

1

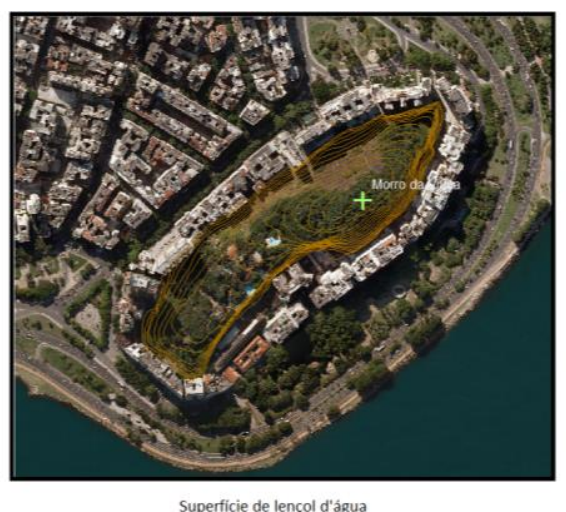

2

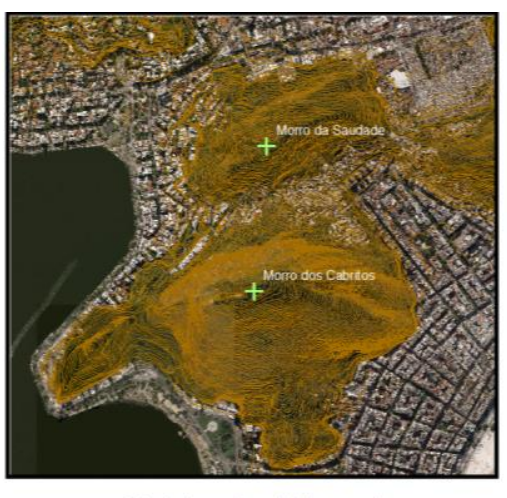

Cota da depressão mais baixa ao redor 3

Figura 2 - Exemplos de áreas com respectivos critérios mais adequados para delimitação.

Os autores Oliveira e Filho (2013, p. 4445), baseando-se nos parâmetros estabelecidos no novo Código Florestal (LEI 12.651/2012) para delimitação de APP de topo de morro, sugerem que o critério a ser utilizado para demarcar a base legal seja "a cota do ponto de cela mais próximo da elevação", propondo assim uma metodologia automatizada para tal. Entretanto, acredita-se que houve um equivoco quanto à 
interpretação do Código Florestal, uma vez que é apenas reafirmado, como na Resolução CONAMA ${ }^{\circ}$ 303, que um dos critérios possíveis é utilizar a cota da depressão mais baixa ao redor - agora de fato considerando-a o ponto de sela -, o que não exclui as outras duas possibilidades. Mas, como estes autores propõem uma metodologia para delimitação em escala regional, é compreensível que essa interpretação tenha sido feita.

Muito similarmente, Victoria et al. (2008) buscando delimitar as APPs em topos de morro para todo o Brasil, opta por utilizar o ponto mais baixo próximo da formação como referência, uma vez que este critério possibilita o uso de uma metodologia baseada em um Sistema de Informação Geográfica, que por sua vez permite que seja realizada uma identificação das bases de morro seguindo um padrão. Novamente, a escala de abrangência direciona a escolha do critério.

Também em Costa et al. - mesmo anterior a Resolução referenciada - é proposto que um único critério seja utilizado para delimitação, sendo este "os locais com declives superiores a $20^{\circ}$, o que corresponde à classe de relevo fortemente ondulado" (1996, p.122). Nesta situação, assim como na proposição de Oliveira e Filho e por Victoria et al., é compreensível a necessidade de utilização de um único parâmetro, pois envolve uma área média/grande com um número desconhecido de formações a serem identificadas.

No caso da cidade do Rio de Janeiro, particularmente, como o número de feições a serem delimitadas é pequeno e, existem Ortofotos Digitais com alta resolução espacial que possibilitam uma observação detalhada, é recomendável que se faça uma análise caso a caso das especificidades de ocorrência para então determinar qual/quais critérios devem ser utilizados para delimitação. Na figura 2 estão exemplificados três casos nos quais se pode notar as situações em que o uso de cada um dos critérios seriam mais adequadamente aplicados para identificação da base.

\section{Resultados e Discussão}

Inicialmente, é importante colocar que no atual Plano Diretor do município Rio de Janeiro existem algumas inconsistências na sessão dedicada aos Sítios de Relevante Interesse Paisagístico e Ambiental. Um dos morros citados, o da Catacumba, não foi localizado no mapa oficial de uso do solo da cidade, elaborado pelo Instituto Municipal de Urbanismo Pereira Passos (2013). Portanto, pode ter havido uma confusão em função da existência de um parque com esse nome no bairro da Lagoa, na área onde se encontra o morro dos Cabritos. Outros casos de prováveis equívocos estão relacionados à nomenclatura dos morros do Portelo, que está indicado no documento como sendo do Portela, e dos Urubus - no bairro do Leme -, que aparece como morro do Urubu, sendo distinguido do outro com o suposto mesmo nome pela Área de Planejamento (AP) onde se localiza. Novamente, em "do Mirante e do Silvério do Amorim" 


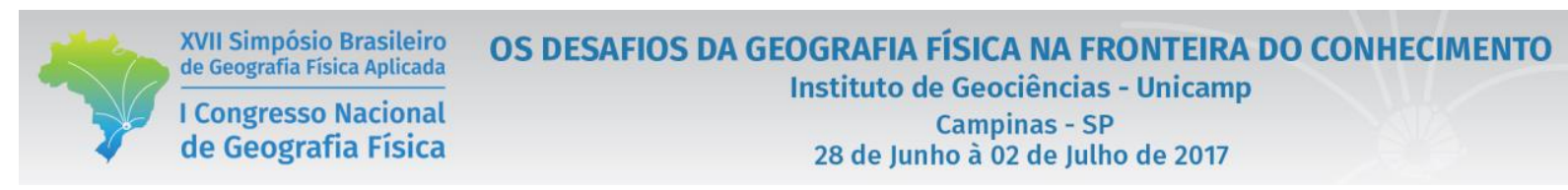

(Lei Complementar 111/2011), é dado margem a uma interpretação errônea. O que poderia ser entendido como apenas dois morros, na verdade, são três.

Além disso, nem mesmo pode-se afirmar categoricamente que os morros listados são, conceitualmente, esse tipo de formação. Entretanto, como aqui é pretendido apenas tratar da delimitação de suas bases, para fins de suporte ao planejamento e gestão do território, e tendo em vista que a existência de um instrumento de proteção já é um grande avanço, essa discussão acerca do rigor conceitual utilizado para nomear tais formações não é aprofundada.

Partindo do fato de que o PDDUS reconhece estes como morros, para a definição de seus limites, foram elencados os critérios mais adequados para cada situação e seus respectivos procedimentos sugeridos para identificação da base (Figura 3). Foi definido, assim, a partir da uma análise espacial realizada, que 9 dos morros listados terão suas bases representadas pela curva de nível que isola a elevação da planície circundante (Critério 1); 1 morro terá sua base delimitada pela curva de nível que isola a elevação em relação ao plano em que se encontra o espelho d'água próximo (Critério 2), e; 20 deles, devido à proximidade com outras elevações - caracterizando uma pequena área com relevo ondulado -, serão limitados pela curva de nível imediatamente superior aquela em que passaria pelo ponto de sela (Critério 3). Neste último caso, é importante ressaltar que é quase impossível que um arquivo de curva de nível nos intervalos regulares - como o de isolinhas disponível na base de dados da Prefeitura - passe pelo ponto de sela, uma vez que este geralmente encontra-se em uma cota com números não exatos (CORTIZO, 2007, p. 5), o que justifica a utilização da cota superior para identificação manual, e em escala local. As curvas de nível a serem usadas para tal procedimento serão as de menor intervalo encontrado na Base Cartográfica da Prefeitura. Na tabela 1 estão discriminados os morros com seus respectivos critérios e, nas figuras 4 e 5, foram espacializados esses mesmos dados.

\begin{tabular}{|l|l|}
\hline Critério & A base do morro corresponderá à: \\
\hline 1 - Planície circundante & curva de nível que isole a elevação em relação a planície. \\
\hline 2 - Superfície de lençol d'água adjacente & $\begin{array}{l}\text { curva de nível que isole a elevação do plano em que se encontra } \\
\text { espelho d'água próximo. }\end{array}$ \\
\hline 3 - Cota da depressão mais baixa ao redor & $\begin{array}{l}\text { curva de nível imediatamente superior aquela em que passaria } \\
\text { pelo ponto de sela. }\end{array}$ \\
\hline
\end{tabular}

Figura 3 - Correlação entre os critérios colocados na Resolução e procedimento proposto para delimitação. 
XVII Simpósio Brasileiro de Geografia Fisica Aplicada

I Congresso Nacional de Geografia Física
OS DESAFIOS DA GEOGRAFIA FÍSICA NA FRONTEIRA DO CONHECIMENTO Instituto de Geociências - Unicamp

Campinas - SP

28 de Junho à 02 de Julho de 2017

Tabela I - Morros e respectivos critérios a serem utilizados para delimitação.

\begin{tabular}{|l|l|l|l|l|l|}
\hline Morro & Critério & Morro & Critério & Morro & Critério \\
\hline da Babilônia & 3 & do Urubu (AP-2) & 3 & do Silvério & 3 \\
\hline dos Coqueiros & 3 & dos Cabritos & 3 & do Mirante & 1 \\
\hline da Saudade & 3 & da Estação & 1 & Panela & 3 \\
\hline da Urca & 3 & do Retiro & 3 & do Bruno & 3 \\
\hline da Viúva & 2 & do Taquaral & 3 & do Camorim & 3 \\
\hline de São João & 3 & da Posse & 3 & do Cantagalo (AP-4) & 1 \\
\hline do Cantagalo (AP-2) & 3 & das Paineiras & 3 & do Outeiro & 1 \\
\hline do Leme & 3 & do Santíssimo & 3 & do Portela & 1 \\
\hline do Pão de Açúcar & 3 & do Luis Bom & 3 & do Rangel & 1 \\
\hline do Pasmado & 1 & do Amorim & 1 & do Urubu (AP-4) & 1 \\
\hline
\end{tabular}
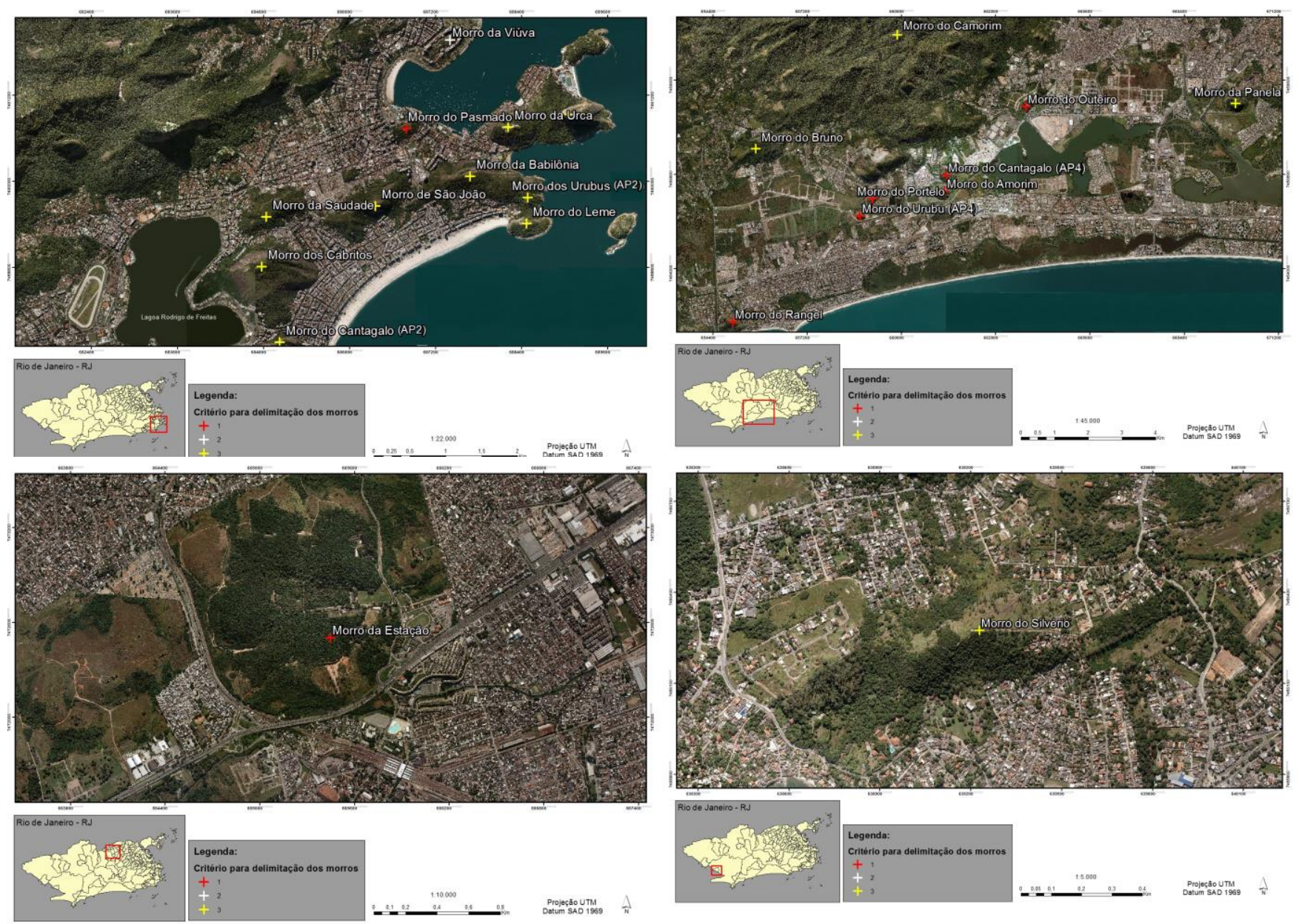

Projectác UTM
Datum SAD 1969

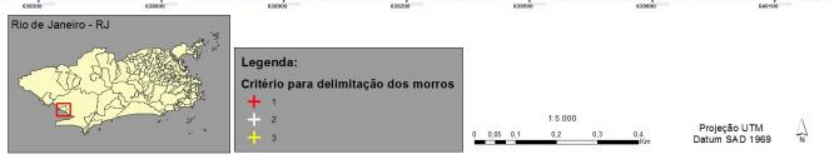

Figura 4 - Representação espacial de 21 morros, diferenciados pelo critério definido para delimitação da base. 


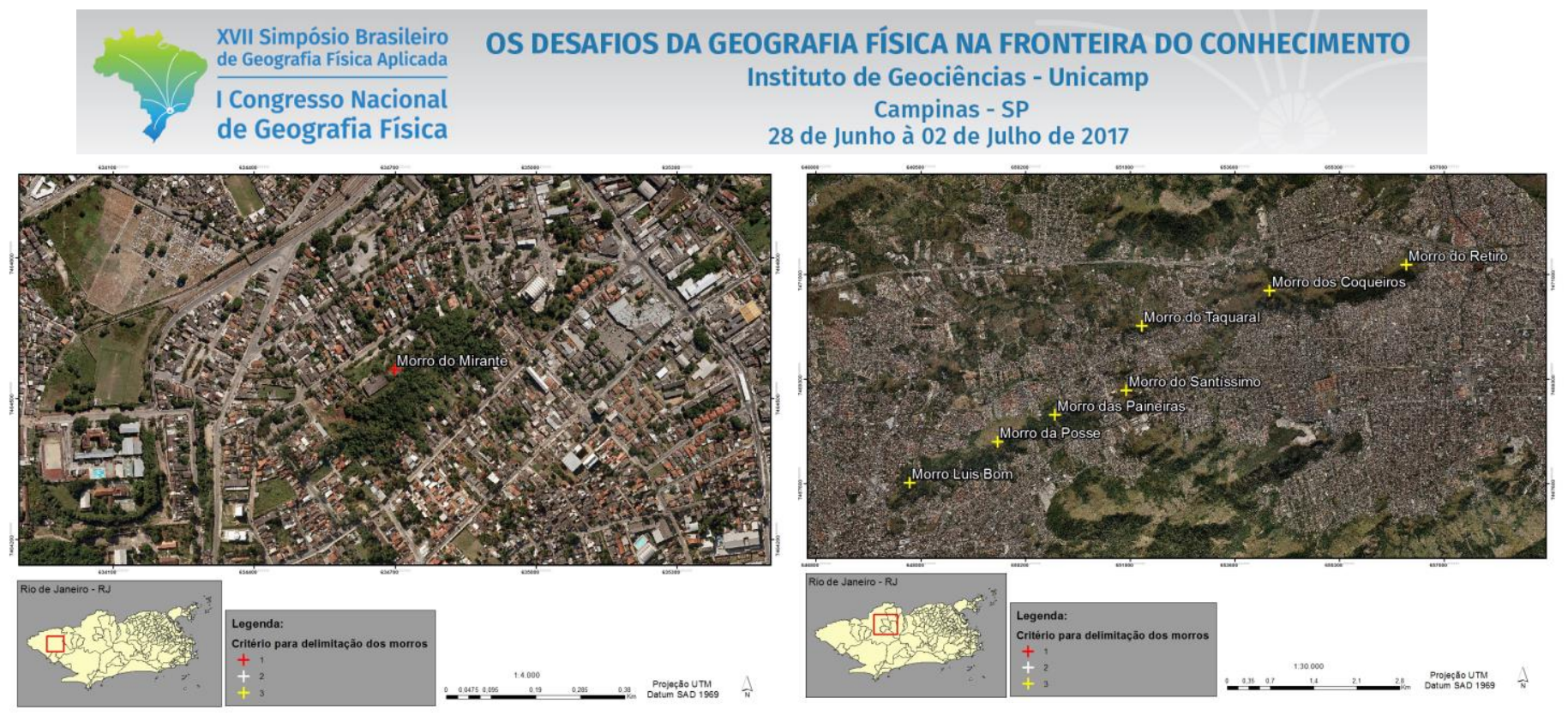

Figura 5 - Representação espacial de 9 morros, diferenciados pelo critério definidos para delimitação da base.

\section{Considerações Finais}

A escala local de abrangência do conjunto de feições a serem delimitadas, que pressupôs uma análise detalhada para que fossem gerados dados mais consistentes, foi um fator determinante para a elaboração deste artigo. Foi constatado na análise realizada que a utilização de um mesmo critério para delimitação de todos os morros não seria adequado, como fizeram alguns autores - para escala regional e de modo automatizado - sugerindo o ponto de sela como referência para toda a extensão pretendida. Desse modo, a indicação feita de utilização dos critérios de acordo com a ocorrência, para escala local e identificação manual das bases, tendo em vista a disponibilidade de Ortofotos Digitais de alta resolução espacial, pode ser considerada satisfatória para atender ao objetivo proposto. Entende-se, portanto, que os critérios eleitos para cada caso contemplaram a variabilidade geomorfológica existente e possibilitarão a realização do procedimento prático sugerido para definição das bases de morro. Em suma, em um contexto mais amplo, esse artigo constituiu uma etapa inicial para o desenvolvimento de um trabalho de conclusão de curso que abarcará as demais feições tidas como SRIPA, assim como um embasamento para a delimitação de uma parte das formações geomorfológicas emblemáticas consideradas áreas protegidas pelo Plano Diretor, que também contribuirá para o incremento nos dados disponíveis da cidade, podendo possuir diferentes aplicabilidades futuras no que tange uma abordagem territorial.

\section{Referência Bibliográfica}

BRASIL. Lei Complementar n ${ }^{\circ}$ 16, de 04 de abril de 1992: Dispõe sobre a política urbana do município, institui o Plano Diretor Decenal da Cidade do Rio de Janeiro, e da outras providências. Rio de Janeiro: Prefeitura do município do Rio de Janeiro.

BRASIL. Lei Complementar $n^{\circ} 111$, de 01 de fevereiro de 2011: Dispõe sobre a Política Urbana e Ambiental do Município, institui o Plano Diretor de Desenvolvimento Urbano Sustentável do Município do Rio de Janeiro e dá outras providências. Rio de Janeiro: Prefeitura do município do Rio de Janeiro. 


$\begin{aligned} & \text { XVII Simpósio Brasileiro } \\ & \text { de Geografia Fisica Aplicada }\end{aligned}$
$\begin{aligned} & \text { I Congresso Nacional } \\ & \text { de Geografia Física }\end{aligned}$

BRASIL. Lei $\mathrm{n}^{\circ} 12.651$, de 25 de maio de 2012: Dispõe sobre a proteção da vegetação nativa; altera as Leis nos 6.938, de 31 de agosto de 1981, 9.393, de 19 de dezembro de 1996, e 11.428, de 22 de dezembro de 2006; revoga as Leis nos 4.771, de 15 de setembro de 1965, e 7.754, de 14 de abril de 1989, e a Medida Provisória no 2.16667, de 24 de agosto de 2001; e dá outras providências. Diário Oficial da União, Brasília, DF (2012).

BRASIL. Resolução CONAMA n 303, de 20 de março de 2002. Dispões sobre parâmetros, definições e limites de Áreas de Preservação Permanente. Diário Oficial da União.

CORTIZO, S. Topo de Morro na Resolução CONAMA n³03. 05 de agosto de 2007. Disponível em: http://www.mma.gov.br/port/conama/processos/FBF21C00/topo1.pdf. Acesso em: Jan. 2017.

COSTA, T. C. C.; SOUZA, M.G.; BRITES, R. S. Delimitação e caracterização de áreas de preservação permanente, por meio de um sistema de informações geográficas (SIG). ln: SIMPÓSIO BRASILEIRO DE SENSORIAMENTO REMOTO, 8. 1996, Salvador. Anais ... São José dos Campos: INPE. Artigos p. 121-127.

OLIVEIRA, G. C.; FILHO, E. I. F. Metodologia para delimitação de APPs em topos de morros segundo o novo Código Florestal brasileiro utilizando sistemas de informação geográfica. In: SIMPÓSIO BRASILEIRO DE Sensoriamento Remoto, 16. 2013, Foz do Iguaçu. Anais... São José dos Campos: INPE. Artigos p. 4443-4450.

VARJABEDIAN, Roberto; MECHI, Andréa. As APPS DE TOPO DE MORRO E A LEI 12.651/12. In: 14 CONGRESSO BRASILEIRO DE GEOLOGIA DE ENGENHARIA E AMBIENTAL. Disponível em: http://www.mpsp.mp.br/portal/page/portal/projeto_florestar/Florestar/material-

apoio/As_APPs_de_Topo_de_Morro_e_a_Lei_12651-12.pdf. Acesso em: Jan. 2017.

VICTORIA, D. C.; HOTT, M. C.; MIRANDA, E. E.; OSHIRO, O. T. Delimitação de áreas de preservação permanente em topos de morros para o território brasileiro. Rev Geogr. Acadêmica v.2 D.2 (víii.2008) p. 66-72. 